\title{
Irrupción vecinal y transformación urbana. El Río Turia como escenario.
}

\author{
Ana Portalés Mañanós ${ }^{1}$, \\ Asenet Sosa Espinosa ${ }^{2}$, Maria TeresaPalomares Figueres ${ }^{3}$ \\ ${ }^{12}$ Departamento de Urbanismo. ${ }^{3}$ Departamento de Composición Arquitectónica. \\ Universidad Politécnica de Valencia, Valencia, España \\ E-mail: 1anporma@urb.upv.es, ${ }^{2}$ assoes@urb.upv.es, \\ ${ }^{3}$ mapafi@cpa.upv.es
}

\begin{abstract}
Resumen. El proceso de movilización vecinal, surgida espontáneamente, en la década de los años setenta, en la ciudad de Valencia, España, bajo la reivindicación de transformación del antiguo cauce del río Turia en Jardín, constituye un hito en la lucha por la conservación del espacio significativamente construido en la ciudad, del patrimonio natural y socio-cultural valenciano.

Este artículo pretende, desde la concepción de la política como práctica colectiva-, realizar una reflexión acerca de los movimientos vecinales que irrumpen e impulsan dicha transformación, acontecidos al final de la dictadura franquista, es decir, cuando aún no existían derechos constitucionales, incidiendo en su relevante importancia ya que tienen como resultado convertir a esta ciudad en una urbe articulada a través de un gran jardín lineal, un parque de escala municipal y supramunicipal. Para ello se recurre a la explotación de fuentes documentales históricas provenientes de instituciones públicas $y$ hemeroteca de prensa. En el centro de dicha reflexión se sitúa la moderna concepción de gobernanza de la ciudad que, entre sus caballos de batalla, tiene a la participación de la ciudadanía en la toma de decisiones, sobre su presente y su futuro, como eje.
\end{abstract}

Palabras clave: participación ciudadana, transformación urbana, parques ciudad, Valencia, Jardín del Turia.

\section{Fundamentos de partida}

La gobernanza del territorio y la ciudad, entendida esta como una nueva forma de gobernar más cooperativa, dirigida a alcanzar un mayor equilibrio entre el poder político y la sociedad a través de la incorporación de la pluralidad de actores, tanto públicos como privados, que pueden participar en la formulación de la política, tiene entre sus caballos de batalla la participación ciudadana en los procesos de gobierno.

En el estudio del espacio público y las transformaciones acaecidas en el mismo fruto de las decisiones que afectan a la ciudad, se hace esencial entender la política urbana como una práctica colectiva (Vallés, 2002: 18), lo cual deviene en asumir la necesaria activación y militancia de la ciudadanía en la conformación y transformación de dicho espacio en el que habita, pues la política tiene carácter ciudadano y la ciudanía tiene carácter político (Pindado, 2008: 25).

La participación activa ciudadana en los procesos de planificación y regeneración urbana se potencian hoy en las ciudades españolas, pasando esta a formar parte de dicho proceso como sujeto y no objeto o simple administrado.

La activación de la ciudadanía, para la gestión y toma de decisiones que afectan a la colectiva, puede realizarse de varias formas entre las que se encuentran: por invitación o top- 
down - cuando el Estado o las Instituciones Públicas invitan a participar-y por irrupción (Pares, 2014: 72) o bottom-up - cuando la sociedad civil decide participar y se organiza para ello- - . En este segundo caso, es cuando emerge el carácter político de la ciudadanía, conformando movilizaciones ciudadanas con un fuerte significado político, constituyendo una dinámica de democratización de la vida colectiva y, por extensión, del crecimiento de la dimensión civil de la sociedad, frente a los procesos vinculados con el Estado (Johnston, et.al., 2001: 7). Es en el marco de la irrupción ciudadana para la participación en la toma de decisiones sobre las actuaciones en el espacio urbano y la planificación urbanística donde se inscribe este trabajo.

Valencia, la llamada ciudad del Turia, cuenta con notables ejemplos históricos del s. XX en los que sus habitantes se han implicado, irrumpiendo mediante movilizaciones en grandes procesos de transformación urbana, contextualizadas en un momento político en el que la instauración de la democracia como modelo de gobierno era un sueño, no existían derechos constitucionales básicos que fundamentasen la participación de la ciudadanía en la toma de decisiones que afectan a su vida. Aunque, al parecer, dichos derechos sí que estaban arraigados en la conciencia civil colectiva, e impulsan la organización vecinal para conseguir un cambio en la relación sociedad civil-Estado al respecto de la transformación de su espacio público, su río.

Así, para abordar la reflexión, objeto de este trabajo, acerca del movimiento vecinal que acontece en esta época en Valencia fruto de la intención, desde el Estado centralista franquista, de la modificación del uso del cauce del río Turia a su paso por la ciudad, a expensas del sentir valenciano, se ha recurrido a la explotación de fuentes documentales históricas provenientes de instituciones públicas y hemeroteca de prensa. La información recogida sitúa la moderna conceptualización de la gobernanza de la ciudad junto a prácticas sociales acontecidas antes de su concepción, en Estados centralistas dictatoriales y a pesar de ellos.

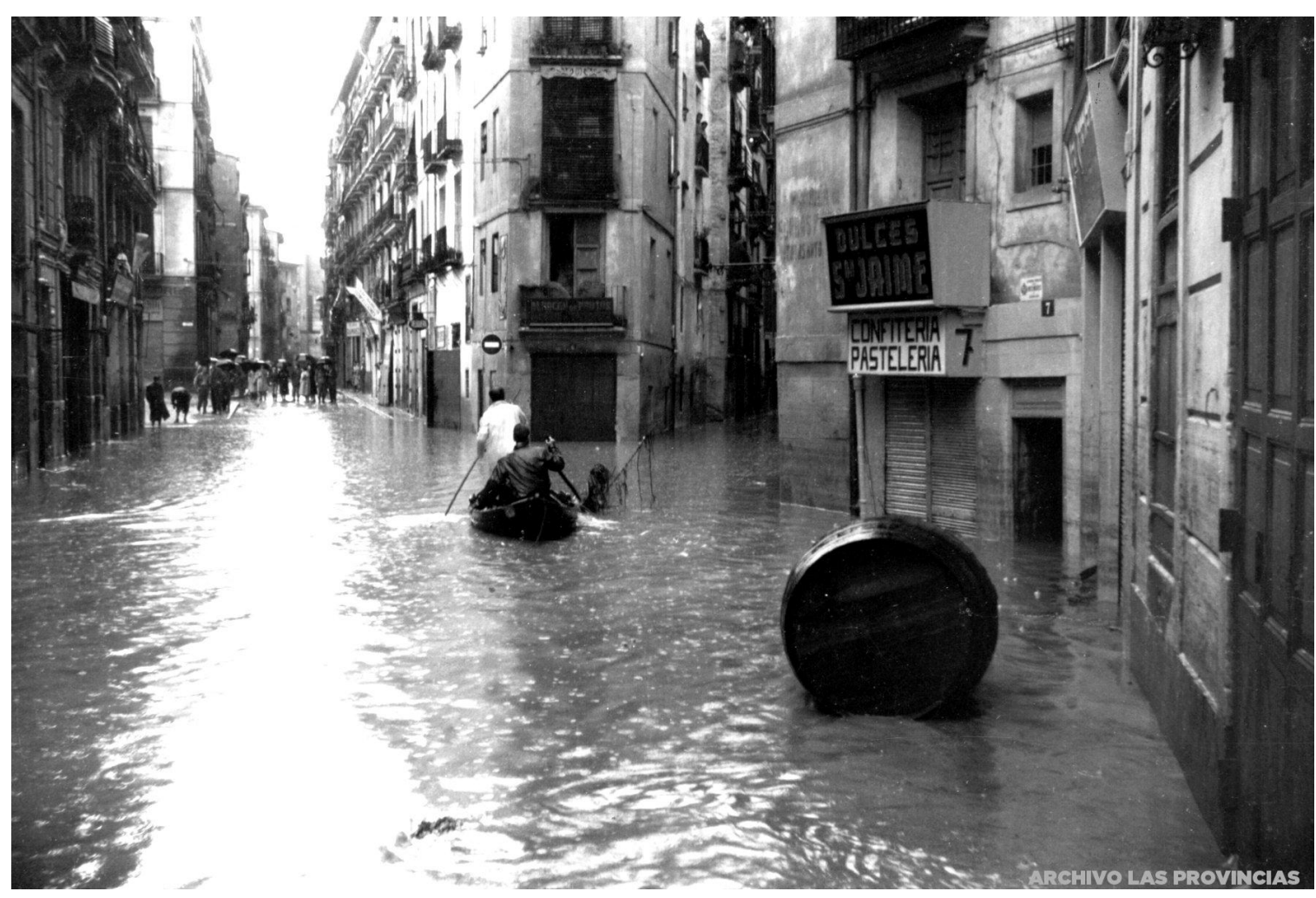

Fig. 1. Riada de 1957 en Valencia (Fuente: Valenpedia. La hemeroteca valenciana) 


\section{Río, sociedad y Ciudad}

El río se encuentra en el centro de la evolución histórica, el desarrollo y el crecimiento económico de Valencia y su región, es parte del nosotros identitario de esta sociedad, lleno de posibilidades y oportunidades vitales para la población de su área de influencia. Así, Valencia, su rio, ciudad y sociedad, constituyen una unidad socio-territorial, ambiental y paisajística.

A su paso por la ciudad recogía escaso caudal, convirtiéndose en el protagonista de numerosas actividades que se arraigaron en la tradición como la celebración de la Pascua, exhibiciones de ganado, ligas deportivas y fiestas populares, e incluso, dio cobijo a asentamientos chabolistas en la posguerra española. Pero eran innumerables las riadas catastróficas, con altos costes en vidas, destrucción de viviendas (Quirós, 2007: 28) y de la economía local, que se sucedían a lo largo. En 1957, tras la última riada, el gobierno de España, junto al municipal, deciden que se ha acometer el desvío del cauce a su paso por la ciudad, intervención que venía proponiéndose desde el s. XIX y que se retoma (Palomares, 2010).

Al año siguiente, es aprobado en Consejo de Ministros (22 de julio de 1958), el Plan Sur, solución surgida de un planteamiento estrictamente hidráulico, la creación de un nuevo cauce de 12.692 metros de longitud y 200 de anchura capaz de desaguar un caudal de $5.000 \mathrm{~m} 3 / \mathrm{seg}$., suponiendo un cambio ambiental de primer orden al liberar al antiguo cauce de la función hidráulica, y su condición natural, no contemplándose como un espacio de inundación ocasional o complementaria al nuevo cauce (Carmona, 2008: 55). Por ello, pronto resultó evidente la necesidad de una completa revisión del planeamiento y la planificación urbana, derivado de las modificaciones que introducía en la estructura urbanística (Gaja y Boira, 1994: 74), ya que el traslado de esta infraestructura demandaba realizar conexiones complementarias: carreteras, líneas de ferrocarril, colectores, acequias, etc. Se redacta un nuevo Plan General de Ordenación Urbana, aprobado en 1966, en el que se proyecta un nuevo uso para el antiguo

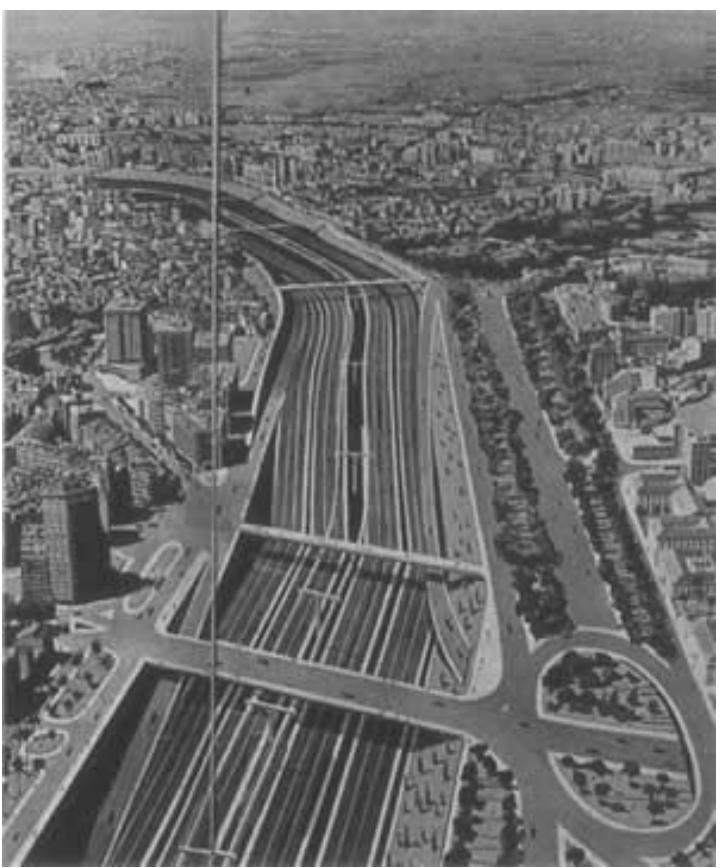

Fig. 2. Perspectiva aérea de la autopista proyectada en el lecho del cauce entre 1966 y 1969 (Fuente: La Gaceta Ilustrada. Madrid, septiembre 1968)

cauce: la creación de una vía sensiblemente Este-Oeste que atraviesa la ciudad, de tráfico rápido. Quedando transformado en una auténtica macro-autopista, como pieza principal de la red viaria de Valencia, reflejo de la política desarrollista franquista, y su área metropolitana, reconectando las infraestructuras de transporte como señala Simó (2004: 137): "La estación central, vías de ferrocarril y de carretera, se ubicarían en él. Un gran eje, vía rápida de tráfico, recorrería todo su espacio e iría desde el puerto al aeropuerto, intentando canalizar las más importantes vías este-oeste". Rompiendo con ello la significación socio-cultural atribuía al río e hipotecando del futuro de la ciudad.

Este nuevo uso, de infraestructura viaria de gran calado, irrumpe en el sentir valenciano, impulsandocontinuas e intensas movilizaciones ciudadanas tras la aprobación del Plan y en su contra, reclamando el río como zona verde para los valencianos, que cobran mayor fuerza a raíz del Real Decreto del 1 de diciembre de 1976, el cual señala que la cesión gratuita (más de un millón de metros cuadrados) de los terrenos del río al Ayuntamiento, por el Estado, no son exclusivos para parques públicos, son también para red viaria . 
En la última etapa de la dictadura franquista, las oportunidades de participación que el estado del sistema político posee durante esa etapa, hace que, como califica Torres (2004), estos movimientos tuvieran mucha fuerza y con intensa carga política. Por lo que, junto al clima de agitación social generalizada de la época, se le unirá el fuerte efecto causado en el sentir valenciano, de la solución de incorporar una autopista en cauce de su río. En palabras de Díaz (2010: 279), "Las heridas dejadas por el franquismo en la ciudad eran muy profundas y las expectativas ciudadanas de mejora eran proporcionales a ellas". La protesta organizada, movilizando amplios sectores de la población, fue un nuevo fenómeno socio-político de la década de los setenta en las ciudades españolas y particularmente Valencia (Alcalá-Santaella et al. 2011: 203-205).

\section{La irrupción vecinal}

Con el objetivo de decidir el destino de este espacio central y simbólico de la ciudad, en pro de la lucha por un cauce verde, surgió desde la base de la ciudadanía una movilización vecinal por irrupción, es decir con una aproximación bottom-up, que no sólo busca la reivindicación y el bloqueo de la propuesta del Estado, sino que, además, construye propuestas desde su propia iniciativa y las dirige a la Administración responsable.

Para el análisis y la reflexión del proceso que sigue esta movilización tomaremos aquí, como eje, las cuatro etapas del proceso de politización enunciadas por Vallés (2002: 25-26), que recogemos brevemente: 1) identificación de una distribución desigual de valores y recursos percibidos como inconveniente; 2) implicación de colectivos tras toma de conciencia, expresando demandas, exigencias y propuestas para corregir la situación de riesgo; 3) búsqueda de aliados entre otros actores sociales y movilización de apoyos y recursos; 4) traslado del conflicto al escenario público, reclamando medidas vinculantes para toda la comunidad.

Extraídos de la documentación histórica consultada, los pasos que siguieron se sintetizan en los siguientes:

1. El inicio se produce a través de reuniones impulsadas por asociaciones de vecinos, destacando en su origen las de los barrios de Russafa y Torrefiel que identifican los inconvenientes y riesgos.

2. Esta toma de conciencia los lleva a la Creación de la Comisión Ciudadana Procauce, en marzo de 1977. Surge a partir de profesionales y expertos, que militan también en asociaciones vecinales: Carmen Jordá, Joan Olmos; Trinidad Simó, Miguel Gil Corell, Justo Ramírez y Miguel Arráiz, convertidos en el eje de la promoción del movimiento. Esta Comisión supone la creación de una organización de ciudad, integradora, con visión de la ciudad como un sistema, necesaria para superar el trabajo concreto barrio a barrio. Estructura su acción con carácter multifuncional, concentrada en el año 1977 :

a) De información, difusión, captación e implicación de la sociedad civil. Conseguir la movilización de apoyos y búsqueda de aliados entre los diferentes actores sociales.

- Organización de actividades con el fin de implicar a otras asociaciones vecinales, a los estudiantes y los vecinos, así como a instituciones urbanas no gubernamentales de alto prestigio socio-político y económico: Sociedad de Amigos del País, Ateneo Mercantil, Colegios profesionales, etc.).

- Actividades lúdicas populares ubicadas en el lecho del cauce, al calor de la tradición popular de uso del río: la fiesta del cachirulo y meriendas tradicionales en Pascuas, competencias deportivas, entre otras. Que serán objeto de la petición popular (1977), generando eslogan como: "el río para el que lo merienda"

b) Comisiones de trabajo internas, en las que se profundizaba en diferentes temas: medioambientales, urbanísticos, etc.

c) De carácter administrativo-urbanístico, ambiental y participativo: informes, peticiones y propuestas. Destaca el escrito de Peticiones al Ayuntamiento, en abril de 1977, cuyo objetivo general fue "recuperar para el patrimonio colectivo los terrenos del antiguo cauce", que solicita acciones como las siguientes :

- 1. Ampliar la cesión desde el arranque de desviación del nuevo cauce hasta el mar.

- 2. Modificar del P.G.O.U., cambiando la denominación autopista «Madrid-Levante» de los terrenos del cauce, y calificarlos como 
zona verde.

- 3. Redactar un plan de utilización del cauce consensuado con asociaciones e instituciones ciudadanas, y un plan de conservación del entorno y márgenes del río para evitar la especulación.

- 4. Asumir criterios básicos excluyan usos ajenos al esparcimiento y al recreo, o que puedan aumentar la contaminación atmosférica y sonora, impulsando usos que estimulen la participación de los ciudadanos, potencien la cultura y sufraguen déficits de equipamientos colectivos de la ciudad.

3. Creación del eslogan El llit del Turia es nostre i el volem ver, dando mayor identidad al movimiento pro-cauce verde. Nace a partir de la visita del Rey, Juan Carlos I (en julio de 1977), al que se le presenta esta reivindicación social, aclarando a quién se considerado propietario del río desde el sentir valenciano.

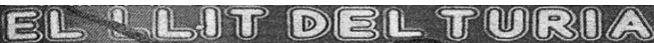 BS0@8Ut?[3 \\ 1) BA NOR BA NER(D)}

Fig. 3. Pegatina con el Lema de las movilizaciones (Fuente: Llopis, 2010: 75)

Hasta aquí, las acciones descritas aluden a la importancia de la unidad entre actores sociales para alcanzar procesos democratizadores.

4. El papel de los medios de comunicación, principalmente de la empresa escrita, que se hacen eco y altavoz de la propuesta adhiriéndose a la misma lucha. Principalmente, desde revistas vinculadas a partidos políticos como Cal Dir - revista del Òrgan Central del Partit Comunista del País Valencià- y el diario local Las Provincias, que rompe con su posición estatalista, a lo largo de la década de los setenta, haciéndose eco de las actividades, movilizaciones y discursos procause, participación que fue significativamente decisiva como altavoz de la reivindicación. Con ello se consigue trasladar el conflicto al escenario público, fundamental en la reclamación de decisiones vinculantes a las instituciones públicas y en el avance hacia procesos democratizadores.

Con lo descrito hasta aquí, descubrimos que este proceso social, transciende la estratificación social e ideológica, cohesionando los diferentes estratos sociales para la consecución de un mismo fin, a lo que le seguirá las fuerzas políticas. Refleja la conciencia democrática existente en la sociedad valenciana en un momento histórico de incertidumbre $\mathrm{y}$ transición política. Así mismo, la preocupación y concienciación sobre el medio ambiente en notable, junto a una cultura urbanística que entiende la ciudad y su río como un todo integrado, de cuya planificación no se puede eximir la participación de sus ciudadanos y ciudadanas en sus procesos de gobierno, en la construcción de su ciudad y su futuro.

\section{Conclusión}

El proceso de movilización social acontecido en la ciudad de Valencia, durante la década de los años setenta, es uno de los episodios de nuestra historia reciente que, además de mostrar la capacidad de auto-organización de la población en la lucha por la conservación de aquellos aspectos que la construyen e identifican como unidad social y cultural, nos retrotraen a la necesidad de avanzar en los ejes y valores de la gobernanza de la ciudad y del territorio en las sociedades actuales, cimentando un modelo de relación sociedad civil-Estado basado en relación más horizontales y menos jerárquicas.

La lucha vecinal por la conversión del Río Turia en Jardín es una lección histórica, cuyo éxito, en parte, se deriva de la estructura organizativa creada y del proceso de politización de la reivindicación del riesgo sentido, durante el que la Comisión Pro-Cauce Verde, parece haber tenido un notable papel en la visibilización del problema al conjunto de la sociedad valenciana, la movilización de apoyos de organizaciones de diferente nivel en la jerarquía social, junto al necesario apoyo de los medios de comunicación.

Este extraordinario episodio es merecedor de análisis y reflexiones profundas, que permitan establecer en qué grado los movimientos sociales y su participación activa pueden ser fundamentales para el proyecto urbano y la concepción urbanística de toda ciudad, y específicamente para Valencia, articulada en la actualidad por un gran parque lineal, una de las mayores infraestructuras verdes urbanas 
españolas. ¿Qué pasó con los movimientos sociales, posteriormente, cuanto España entra en la transición e instaura su democracia?, ¿el protagonismo de los procesos participativos en la configuración del presente y el futuro de la ciudad de Valencia se incentivaron y se caminó a su reconocimiento e institucionalización, o se relajó ante la nueva forma de organizar los poderes en Democracia?¿Hemos olvidado la irrupción social que aconteció en Valencia, ante la trasformación propuesta para su río, hace más de cuarenta años, sus efectos e impactos?. Alcalá-Santaella, (et al, 2011:214) nos recuerda que se abrió un modelo de gobierno neoliberal, de esta ciudad en la década de los noventa, que despolitiza las políticas urbanas. Aunque será, a principios de la década de los años noventa, cuando el principio de Gobernanza, que tiene como uno de sus ejes fundamentales la participación ciudadana, cobre y vaya creciendo hasta trasladarse al gobierno de la ciudad.

El Jardín del Turia está hoy en día monumentalizado, ¿en qué medida se ha ido dando satisfacción a las demandas sociales de los años setenta?, ¿se avanzó en el derecho a la ciudad? Contestar estas preguntar requería investigación de mayor calado.

\section{Referencias}

Alcalá-Santaella, Felipe; Díaz Orueta, Fernando; Ginés, Xavier y Lourés, $M^{\mathrm{a}}$ Luisa. 2011. "VIII. Valencia". En Políticas urbanas en España. Grandes ciudades, actores y gobiernos locales, 201-227. Barcelona: ICARIA.

Carmona González, Pilar. 2009. "La transformación del río Turia y el litoral deltaico". En La ciudad de Valencia: historia, geografía y arte de la ciudad de Valencia., Vol. 2, Geografía y arte. Universitat de València, España.

Díaz Orueta, Fernando. 2010. "Regímenes urbanos y movimiento ciudadano en Valencia". Cuaderno urbano, 9(9). Universidad Nacional del Nordeste, Argentina

Gaja Díaz, Fernando y Boira Maiques, Josep Vicent (1994) "Planeamiento y realidad urbana en la ciudad de Valencia (1939-
1989)". Cuadernos de Geografía, 55, 63-89. Universitat de València.

Llopis Alonso, Amando L. 2010. "El cauce del río Turia a su paso por Valencia. Historia visual de una conquista ciudadana (18801990)" En Valencia 1957-2007. De la riada a la Copa de América, 61-77. Valencia: Josep Sorribes Ediciones, Universitat de València. Johnston, Hank; Laraña, Enrique y Gusfield, Joseph. 2001. "Identidades, ideologías y vida cotidiana en los nuevos movimientos sociales" En Los nuevos movimientos sociales. De la ideología a la identidad, 3-44. CIS, Madrid

Quiros Palau, Martín. 2007. "En el 50 aniversario de la riada del Turia". Revista de treball, economia i societat, 46, 27-28.

Pares, Marc. 2014. "La participación política de los jóvenes ante el cambio de época: estado de la cuestión". Metamorfosis. Revista del Centro Reina Sofía sobre Adolescencia y Juventud, 0, 65-85

Palomares Figueres, María Teresa. 2010. La producción experimental de GO. DB. arquitectos. Director: Carmen Jordá Such. Universidad Politécnica de Valencia, Departamento de Composición Arquitectónica.

Torres, Vicent. 2004. "Viejos y nuevos movimientos ciudadanos en el País Valenciano". Ponencia presentada al Congreso Movimientos sociales hoy: avanzando hacia una democracia transformadora. Díaz Orueta, F (dir). Universidad de Alicante, Alicante.

Simó, Trinidad. 2004. "Valencia: un crecimiento insostenible". En Urbanismo en el siglo XXI. Bilbao, Madrid, Valencia, Barcelona. Ediciones UPC. Barcelona.

Vallés, Josep M. 2002. Ciencia Política. Una introducción. Barcelona: Ariel. 